\title{
$\alpha-\mathrm{Si}_{3} \mathrm{~N}_{4}$ 粉末の低温熱容量
}

\author{
山下 勲・川路 均・阿竹 徹・山田哲夫*・岡田 清** \\ 東京工業大学応用セラミックス研究所, 226-8503 神奈川県横浜市緑区長津田町 4259 \\ *宇部興産(株)宇部研究所, 755-8633 山口県宇部市大字小串 1978-5 \\ **東京工業大学工学部無機材料工学科, 152-8552 東京都目黒区大岡山 2-12-1
}

\section{Heat Capacity of $\alpha-\mathrm{Si}_{3} \mathrm{~N}_{4}$ Powders at Low Temperatures}

Isao YAMASHITA, Hitoshi KAWAJI, Tooru ATAKE, Tetsuo YAMADA* and Kiyoshi OKADA**

Materials and Structures Laboratory, Tokyo Institute of Technology, 4259, Nagatsuta-cho, Midori-ku, Yokohama-shi $226-8503$

*Ube Research Laboratories, UBE Industries, Ltd., 1978-5, Kogushi, Ube-shi, Yamaguchi 755-8633

**Department of Inorganic Materials, Faculty of Engineering, Tokyo Institute of Technology,

2-12-1, Ookayama, Meguro-ku, Tokyo 152-8552

\begin{abstract}
Thermodynamic properties of highly pure $\alpha=\mathrm{Si}_{3} \mathrm{~N}_{4}$ powders were studied on the samples with different specific surface area $\left(0.33 \mathrm{~m}^{2} \cdot \mathrm{g}^{-1}\right.$ and $\left.11.2 \mathrm{~m}^{2} \cdot \mathrm{g}^{-1}\right)$ prepared by imide decomposition method. The heat capacity was measured by an adiabatic calorimeter between 13 and $300 \mathrm{~K}$, and an anomalous excess heat capacity was observed at about $18 \mathrm{~K}$ for the sample with high specific surface area $\left(11.2 \mathrm{~m}^{2} \cdot \mathrm{g}^{-1}\right) \cdot{ }^{1} \mathrm{H}-\mathrm{NMR}$ was also measured at room temperature, and a peak was observed at $3.7 \mathrm{ppm}$ for the sample with high specific surface area. On the sample, surface $-\mathrm{OH}$ and $-\mathrm{NH}_{2}$ groups were detected by IR measurements. The excess heat capacity was possible to be attributed to the rotational motion about $\mathrm{C}_{2}$ axis of $-\mathrm{NH}_{2}$ group.

[Received December 24, 1998; Accepted February 19, 1999]
\end{abstract}

Key-words : Heat capacity, $\alpha-S i_{3} N_{4},{ }^{1} H-N M R$, Surface state of powder

\section{1. 序 言}

$\mathrm{Si}_{3} \mathrm{~N}_{4}$ 材料は耐熱性, 而摩耗性に優れ, 高強度, 高勒性の工 ンジニアリングセラミックスとして熱機関用の高温部材や機械 部品などへの応用が期待されている. $\mathrm{Si}_{3} \mathrm{~N}_{4}$ 部材の製造におい ては原料粉末の物理的, 化学的性質がスラリ一特性や成形, 焼 結挙動に大きな影響を与えるため, 粉末特性の制御が大きな問 題となっている。一般に $\mathrm{Si}_{3} \mathrm{~N}_{4}$ 粒子の表層部には $\mathrm{SiO}_{2}, \mathrm{Si}_{2} \mathrm{ON}_{2}$ などの酸化物, 酸窒化物が, 最表面にはアミド基 $\left(\mathrm{Si}-\mathrm{NH}_{2}\right)$ やシラノール基 ( $\mathrm{Si}-\mathrm{OH})$ などの表面官能基1)が存在し，それ らがスラリー特性や焼結挙動を左右する要因の一つと考えられ ている.したがってこの粒子表面の状態を物理化学的に解明し てゆくことが重要である. 本研究では, イミド熱分解法で合成 された比表面積の異なる高純度 $\alpha-\mathrm{Si}_{3} \mathrm{~N}_{4}$ 粉末の低温熱容量測定 を行い，粒子表面の化学種が熱容量に与える影響を考察した。 また粒子表面の化学種を調べる目的で ${ }^{1} \mathrm{H}-\mathrm{NMR}$ 測定及び IR 測定を行った。

\section{2. 実 験}

\section{1 試料調製}

本研究に用いた試料は，イミド熱分解法2)により宇部興産に て合成されたものである，本研究では比表面積の異なる 2 種 類の $\alpha-\mathrm{Si}_{3} \mathrm{~N}_{4}$ 粉末を用いた. 以下，これらを試料 $\mathrm{A}, \mathrm{B}$ と記す.

Table 1. Characteristics of the $\alpha-\mathrm{Si}_{3} \mathrm{~N}_{4}$ Powders

\begin{tabular}{cccc}
\hline Sample & Specific surface & Mean particle & 0xygen content \\
& area & size & $/$ mass \% \\
& $/ \mathrm{m}^{2} \mathrm{~g}^{-1}$ & $/ \mu \mathrm{m}$ & \\
\hline $\mathrm{A}$ & 0.33 & 10 & 0.36 \\
$\mathrm{~B}$ & 11.2 & 0.6 & 1.26 \\
\hline
\end{tabular}

試料 A, B の比表面積, 平均粒径, 不純物酸素量を表 1 に示 す，ここで比表面積は BET1 点法, 平均粒径は遠心沈降法に より測定した。また不純物酸素量は，不活性ガ久溶融法で試料 を分解し，発生した $\mathrm{CO}_{2}$ を赤外線検出法で定量して求めた (LECO 法).

\section{2 熱容量測定}

試料 A, B について, 研究室既設の断熱型熱量計 3 をを使用し て，13〜300 K の温度領域で熱容量を測定した。いすれの試 料も熱容量測定に先立ち, ロータリーポンプ, 液体窒素トラッ

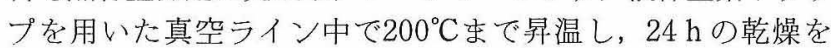
行った。

熱容量測定に用いた試料量は，それぞれ試料 A : 0.075258 $\mathrm{mol}(10.557 \mathrm{~g})$, 試料 B : $0.043581 \mathrm{~mol}(6.1136 \mathrm{~g})$ である. いずれの試料についても熱容量測定用セルに入れ，室温で $2 \sim 3 \mathrm{~h}$ 真空排気した後, 熱交換用のヘリウムガス約 $8 \mathrm{kPa}$ を 導入して封じた。

\section{$2.3{ }^{1} \mathrm{H}-\mathrm{NMR}$ 測定及び IR 測定}

試料 $\mathrm{A}, \mathrm{B}$ に含まれると考えられる水素原子について調べる 目的で，室温で ${ }^{1} \mathrm{H}-\mathrm{NMR}$ 测定を行った。測定は Bruker DSX300を用い, 積算回数 : 1000, 積算時の繰り返し時間 : $1 \mathrm{~s}$, $90^{\circ}$ パルス幅 : $2.00 \mu \mathrm{s}$ の条件で行った. 化学シフトの基準物 質にはテトラメチルシラン (TMS) を用いた.

用いた試料量はそそれぞれ試料 $\mathrm{A}: 0.20 \mathrm{~g}$ ，試料 B: $0.47 \mathrm{~g}$ である。

試料 B の表面官能基について情報を得るために，室温で拡 散反射法によるIR 測定を行った．測定は FT-IR8600PC（島 津製作所）を用い, 積算回数: 40 , 波数分解能 : $4.0 \mathrm{~cm}^{-1}$, 測定範囲 : $400 \mathrm{~cm}^{-1} \sim 4000 \mathrm{~cm}^{-1}$ の条件で行った。試料 B 之 $\mathrm{KBr}$ 粉末を約 $1: 5$ の割合で混合し, 乾燥空素ガス雲囲気中で 測定を行った. 


\section{3. 結 果}

\section{1 熱容量測定}

試料 $\mathrm{A}, \mathrm{B}$ の熱容量測定の結果を図 1 に示す. $\mathrm{Si}_{3} \mathrm{~N}_{4}$ の化学 式量 $1 \mathrm{~mol}$ 当たり $7 N_{\mathrm{A}}$ の原子が含まれるので，格子振動の自 由度は $3 \times 7 N_{\mathrm{A}}=21 N_{\mathrm{A}}$ である。したがって, Dulong-Petit の 古典論から求められる $\mathrm{Si}_{3} \mathrm{~N}_{4}$ の熱容量は $21 R=174.6 \mathrm{JK}^{-1}$. $\mathrm{mol}^{-1}$ である。しかし室温における熱容量の実測值は約 92 $\mathrm{JK}^{-1} \cdot \mathrm{mol}^{-1}$ であり，21Rよりもかなり小さい. 図 2 には, こ れまでに報告されている高温領域のデータ4) とを併せて示し た. 図 2 を見ると熱容量は約 $2000 \mathrm{~K}$ 付近で古典値に飽和して いることが分かる．つまりこの物質は原子間の力定数の大きな 非常に硬い結晶であると言える.

試料 A, B の熱容量は，全体的にはほほ一致している。しか

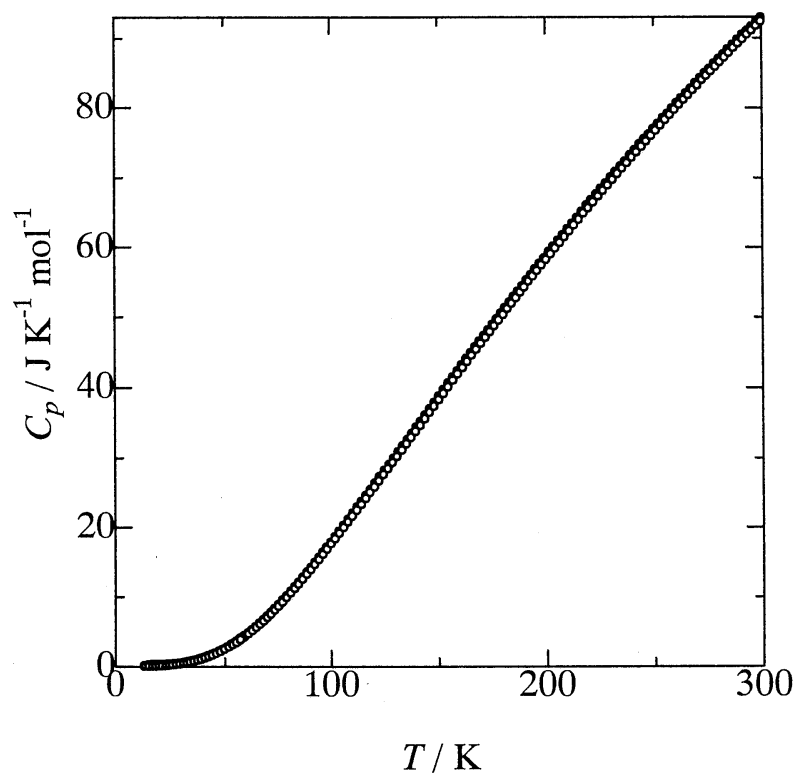

Fig. 1. Heat capacity of $\mathrm{Si}_{3} \mathrm{~N}_{4}$ powders $\left(\bigcirc\right.$ Sample A $\left(0.33 \mathrm{~m}^{2}\right.$ $\left.\mathrm{g}^{-1}\right)$, Sample B $\left.\left(11.2 \mathrm{~m}^{2} \cdot \mathrm{g}^{-1}\right)\right)$.

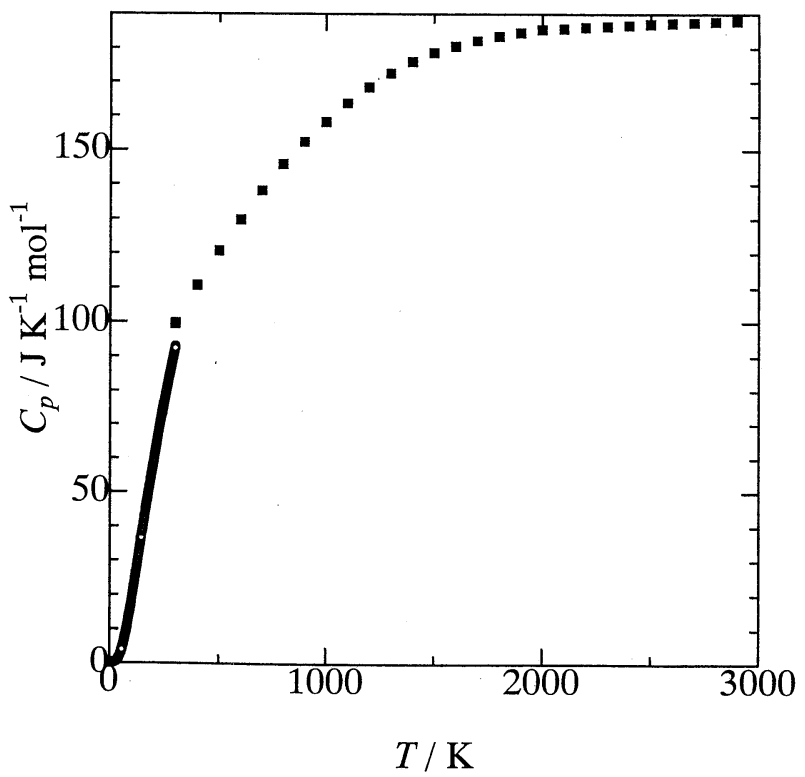

Fig. 2. Heat capacity of $\mathrm{Si}_{3} \mathrm{~N}_{4}\left(\bigcirc\right.$ Sample $A\left(0.33 \mathrm{~m}^{2} \cdot \mathrm{g}^{-1}\right)$, M. W. Chase et al.4)
しながら図 3 に示すように低温領域を拡大すると，高比表面積 の試料 B では $25 \mathrm{~K}$ 以下にこぶ状の過唾熱容量があることが分 かる. 試料 B の熱容量から試料 $\mathrm{A}$ の熱容量を差し引くと図 4 が得られる. $18 \mathrm{~K}$ 付近に過剩熱容量のピークがあり，更にそ の高温側では，温度とともに熱容量の差が増加する傾向にある ことが分かる．この詳細については 4 章で考察する．この熱 容量測定の結果, 高比表面積の試料 B で低温に大きな熱異常 が観測されたが，これは粒子表面の不純物，吸着種などによる ものと考えられることから，以下の測定を行った。

\section{$3.2{ }^{1} \mathrm{H}-\mathrm{NMR}$ 測定}

試料 A, B についての ${ }^{1} \mathrm{H}-\mathrm{NMR}$ 測定の結果を図 5 に示す. 比較のため縦軸の強度は，単位重量で換算してめる．高比表面 積の試料 B では, $3.7 \mathrm{ppm}$ 付近に鋭いピークが観測された.こ

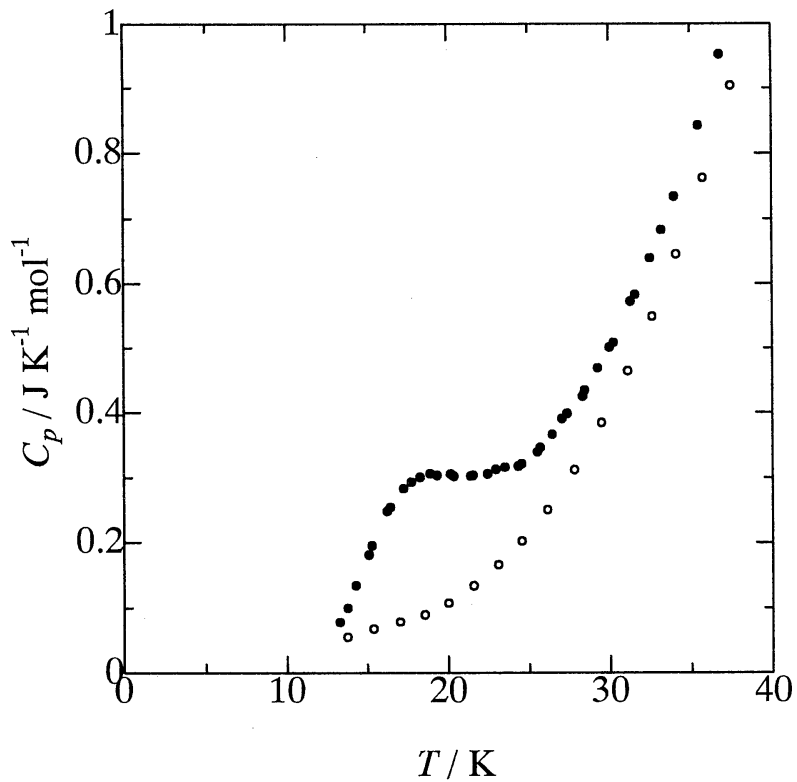

Fig. 3. Heat capacity of $\mathrm{Si}_{3} \mathrm{~N}_{4}$ powders in the low temperature region $\left(\bigcirc\right.$ Sample A $\left(0.33 \mathrm{~m}^{2} \cdot \mathrm{g}^{-1}\right)$, Sample B $\left(11.2 \mathrm{~m}^{2} \cdot \mathrm{g}^{-1}\right)$ ).

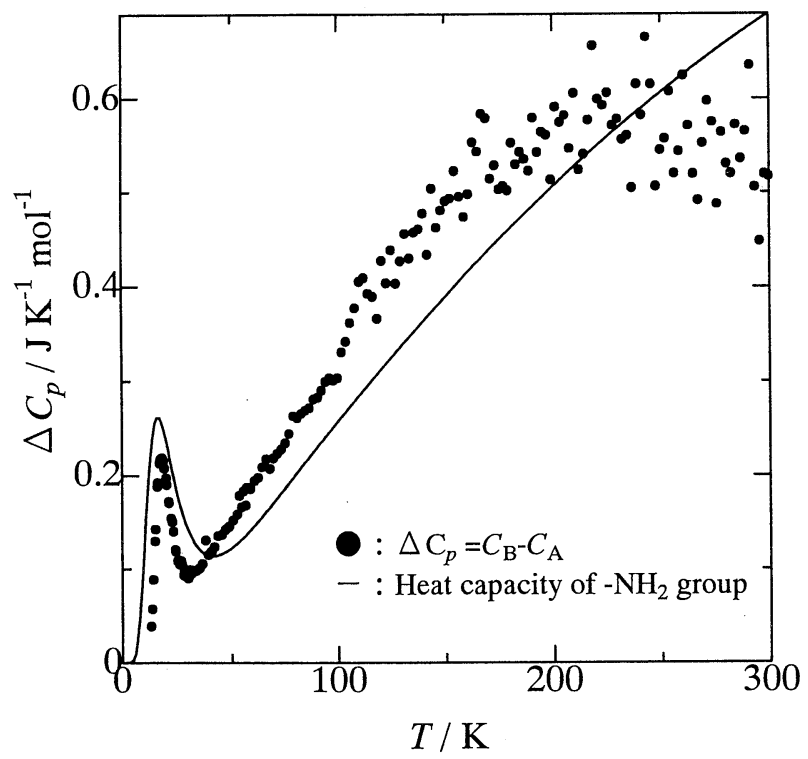

Fig. 4. Heat capacity difference between Sample B $\left(11.2 \mathrm{~m}^{2} \cdot \mathrm{g}^{-1}\right)$ and Sample A $\left(0.33 \mathrm{~m}^{2} \cdot \mathrm{g}^{-1}\right)$. 


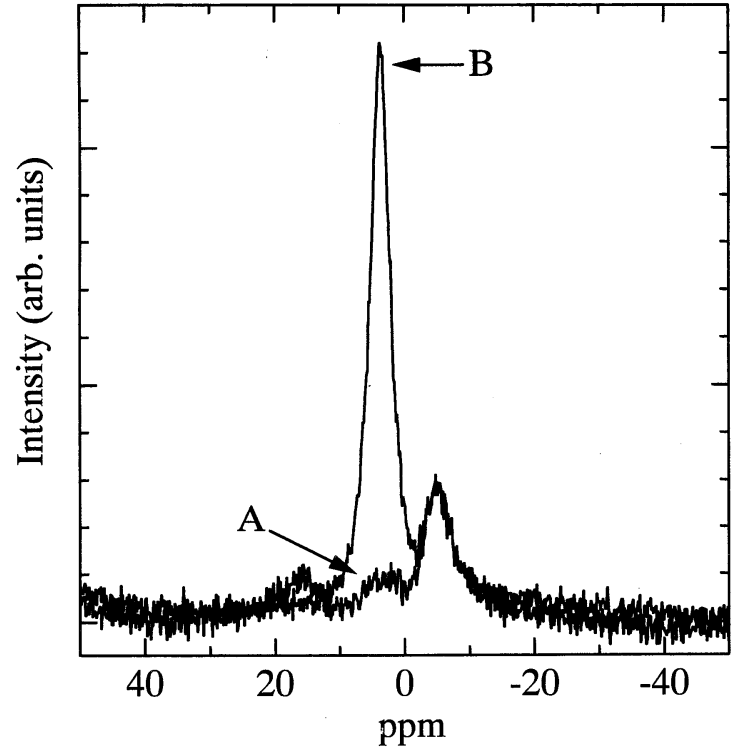

Fig. 5. ${ }^{1} \mathrm{H}-\mathrm{NMR}$ spectra of $\mathrm{Si}_{3} \mathrm{~N}_{4}$ powders.

Table 2. Ratios of ${ }^{1} \mathrm{H}-\mathrm{NMR}$ Peak Intensity at $3.7 \mathrm{ppm}$ and Specific Surface Area of $\alpha-\mathrm{Si}_{3} \mathrm{~N}_{4}$ Powders

\begin{tabular}{ccc}
\hline Sample & A & B \\
\hline${ }^{1}$ H-NMR peak intensity & 1 & 22.7 \\
Specific surface area & 1 & 33.9 \\
\hline
\end{tabular}

れに対して低比表面積の試料 A では, このピークは小さくなっ ている.これらのピーク強度と比表面積の比を表 2 に示す. な抢試料 B の $15 \mathrm{ppm}$ 付近に現れた小さなピークは, $3.7 \mathrm{ppm}$ のスピニングサイドバンドである． また試料 $\mathrm{A}, \mathrm{B}$ の両者とも $-5.2 \mathrm{ppm}$ 付近にピークが現れているが，これらはほほ同じ強 度であるので, 測定上の問題によるものと考えられる.

$3.7 \mathrm{ppm}$ に観測されたピークの強度比と比表面積の比がほほ 対応していることと，Yeu ら5)による ${ }^{1} \mathrm{H}-\mathrm{NMR}$ を用いた $\mathrm{Si}_{3} \mathrm{~N}_{4}$ 粒子表面の研究報告を考え併せると，このピークは粒子 表面上に存在する表面官能基に含まれる水素原子によるものと 考えられる.すなわち粒子表面には比表面積に比例した一定割 合の含水素化合物が存在しており，3.7 ppm に吸収ピークを持 つものと考えられる.

\subsection{IR 測定}

${ }^{1} \mathrm{H}-\mathrm{NMR}$ 測定から，粉末試料には水素原子が含まれること が確認された，そこで，粒子表面に存在する表面官能基を同定 するために，室温で試料 B の IR 測定を行った，測定結果を 図 6 に示す.

Ramis $5^{6}$ ) は, $\mathrm{Si}_{3} \mathrm{~N}_{4}$ 微粉末（比表面積 $65 \mathrm{~m}^{2} \cdot \mathrm{g}^{-1}$ ) の IR 測 定を行い，さまざをな表面官能基の吸収特性を報告している. それによると $3740 \mathrm{~cm}^{-1}$ 付近のバンドはー $\mathrm{OH}$ 基の伸縮振動に よるものであり, $1560 \mathrm{~cm}^{-1}$ 付近のものは $-\mathrm{NH}_{2}$ 基の変角振 動によるものである. また $3450 \mathrm{~cm}^{-1}$ 付近に現れるブロード なバンドは, $-\mathrm{NH}_{2}$ 基の伸縮振動によるものと考えられる. 以上から粒子表面には $-\mathrm{NH}_{2}$ 基， $-\mathrm{OH}$ 基などが存在し，こ れらの表面官能基の水素原子が ${ }^{1} \mathrm{H}-\mathrm{NMR}$ で検出されたものと 考えられる. また $800 〜 1200 \mathrm{~cm}^{-1}$ 領域の強い吸収は, Si-N-

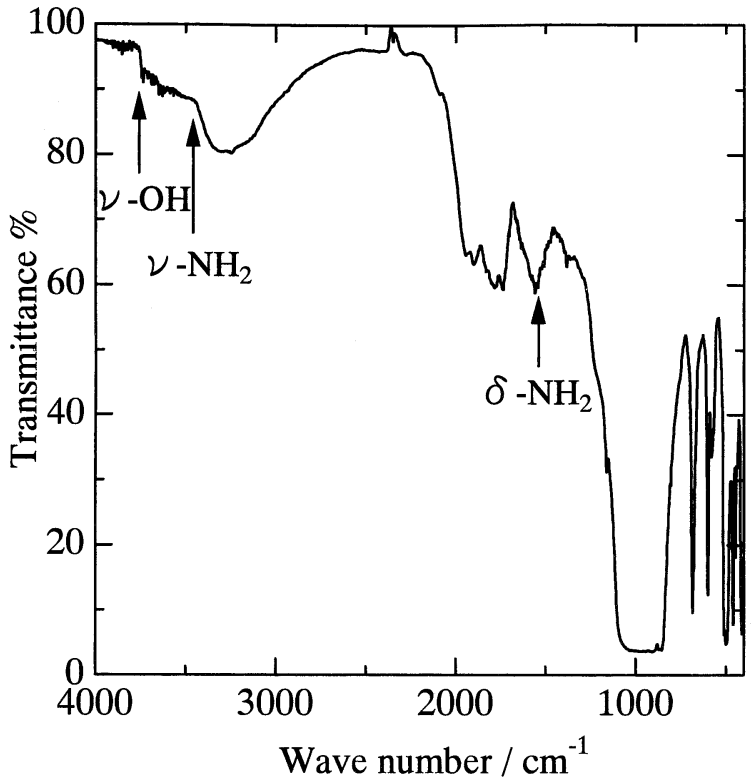

Fig. 6. IR spectrum of Sample B.

$\mathrm{Si}$ 結合の伸縮振動及び $\mathrm{Si}-\mathrm{N}-\mathrm{H}$ 結合の变角振動によるもので ある.なお, $2300 \mathrm{~cm}^{-1}$ 付近の吸収は, 測定雾囲気中の $\mathrm{CO}_{2}$ ガスによるものである.

\section{4. 考 察}

比表面積の異なる 2 種類の $\mathrm{Si}_{3} \mathrm{~N}_{4}$ 粉末の熱容量測定を行った 結果, 高比表面積の試料 B では, $25 \mathrm{~K}$ 以下にこぶ状の過剩熱 容量が観測された。一般に結晶の格子振動による熱容量は Debye の $T^{3}$ 則からの予測と同様, 試料 A の熱容量のように 温度の低下とともに単調に減少し, 滑らかに 0 に向かう. 試 料 Bにあらわれた過剩な熱容量は $\mathrm{Si}_{3} \mathrm{~N}_{4}$ 結晶の格子振動以外 の寄与によるものと考えられる. Markichev ら ${ }^{7), 81}$ は, さまざ まな方法で合成された $\mathrm{Si}_{3} \mathrm{~N}_{4}$ 粉末と, バルクの $\mathrm{Si}_{3} \mathrm{~N}_{4}$ 結晶の中 性子非弾性散乱実験を行い，両者から粒子表面部分の振動の状 態密度を算出している. その結果, $\mathrm{SiCl}_{4}-\mathrm{NH}_{3}$ 系の反応生成物 を分解する方法で合成された $\mathrm{Si}_{3} \mathrm{~N}_{4}$ 粉末には， $400 \mathrm{~cm}^{-1}$ 付近 にー $\mathrm{NH}_{2}$ 基の運動によるピークが現れることを示している. 今回測定した試料は，イミド熱分解法で合成しており, Si$\mathrm{NH}_{2}$ 結合を有する前駆体を経由していることから, 粒子表面 にー $\mathrm{NH}_{2}$ 基などの表面官能基が存在すると考えられる. また 前述の ${ }^{1} \mathrm{H}-\mathrm{NMR}$ 測定及び IR 測定からも粒子表面に $-\mathrm{NH}_{2}$ 基 が存在することが支持されている.このー $\mathrm{NH}_{2}$ 基の運動が過 唾熱容量の原因となっている可能性が考えられる. Markichev らの報告した状態密度を表面の一 $\mathrm{NH}_{2}$ 基によるものと仮定し て熱容量を計算すると $300 \mathrm{~K}$ で飽和せず温度とともに増加する 傾向を示し, 図 4 に示す過剩熱容量が $30 \mathrm{~K}$ 以上で温度ととも に増加する傾向と一致する. しかしながら低温で観測されたこ ぶ状の過剰熱容量は再現できない. そこでー $\mathrm{NH}_{2}$ 基が表面で $\mathrm{C}_{2}$ 軸まわりに自由回転しているというモデルを仮定した. $-\mathrm{NH}_{2}$ 基による熱容量 $C_{-\mathrm{NH}_{2}}$ は $\mathrm{C}_{2}$ 軸まわりの自由回転による 熱容量 $C_{\text {rot }}$ と Markichev の報告した振動の状態密度から計算 される熱容量 $C$ の和として以下のように計算される.

$$
C_{-\mathrm{NH}_{2}}=C_{\mathrm{rot}}+8 C
$$

ここで, $-\mathrm{NH}_{2}$ 基の水素原子の状態が, 回転量子数の偶奇に もかかわらずつねに平衡状態であるとすると, 回転運動による 熱容量 $C_{\text {rot }}$ は, 


$$
C_{\text {rot }}=\frac{\mathrm{d}}{\mathrm{d} T}\left[R T^{2} \frac{\mathrm{d}}{\mathrm{d} T} \ln \left(3 z_{\text {odd }}+z_{\text {even }}\right)\right]
$$

となる. 回転量子数の奇及び偶数に対応する分配関数 $Z_{\mathrm{odd}}$, $Z_{\text {even }}$ は,それぞれ

$$
\begin{aligned}
& z_{\text {odd }}=\sum_{j=1,3,5, \cdots}(2 j+1) \exp \left[-j(j+1) \frac{\Theta_{\mathrm{r}}}{T}\right] \\
& z_{\mathrm{even}}=\sum_{j=0,2,4, \cdots}(2 j+1) \exp \left[-j(j+1) \frac{\Theta_{\mathrm{r}}}{T}\right]
\end{aligned}
$$

である．ここで $\Theta_{\mathrm{r}}$ は, 慣性モーメントによって決まるー $\mathrm{NH}_{2}$ 基の回転運動の特性温度であり, $\mathrm{N}-\mathrm{H}$ 結合距離を $0.1024 \mathrm{~nm}$, $\angle \mathrm{HNH}$ 結合角度を $103.3^{\circ}$ と仮定した結果, この場合は約 $28 \mathrm{~K}$ である。

粒子表面の振動の状態密度から計算される熱容量 $C$ は, $G(\omega)$ を表面部分の状態密度として, 以下のように計算され る.

$$
C=R \int x^{2} \frac{e^{\mathrm{x}} G(\omega)}{\left(e^{\mathrm{x}}-1\right)^{2}} \mathrm{~d} \omega
$$

ここで,

$x=\frac{h \omega}{k_{B} T}$

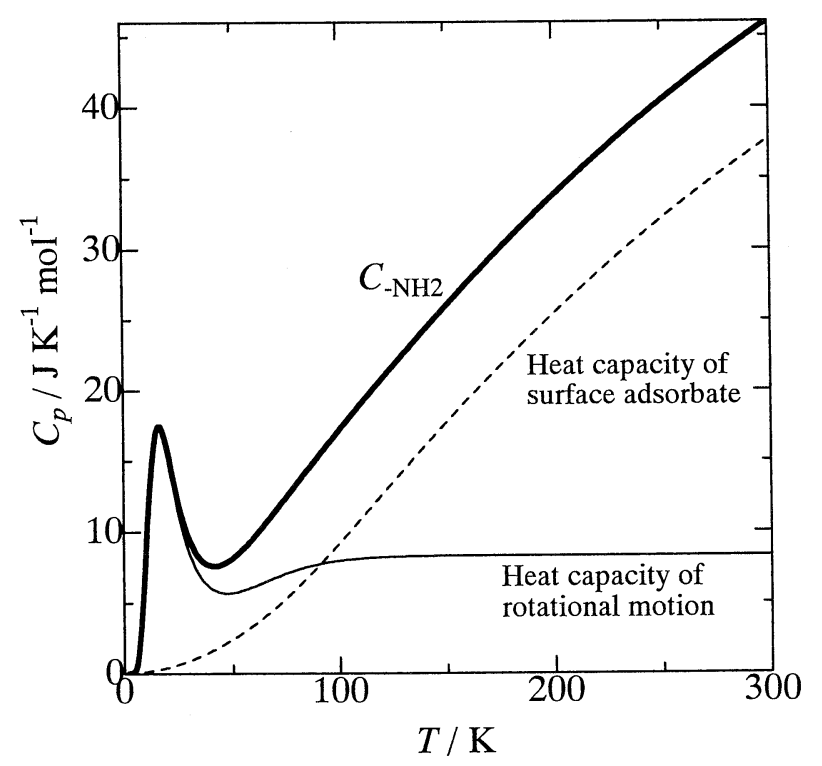

Fig. 7. Calculated heat capacity of $-\mathrm{NH}_{2}$ group.
このようにして熱容量を計算した結果を図 7 に示す，回転運 動による熱容量は, $17 \mathrm{~K}$ 付近にピークを持つカーブとなり， $100 \mathrm{~K}$ 付近で古典値の $R=8.314 \mathrm{JK}^{-1} \cdot \mathrm{mol}^{-1}$ に飽和した. そ れに対し, 状態密度から求めた振動による熱容量は, $300 \mathrm{~K}$ で は飽和せず温度とともに増加した。これら両者の熱容量を足し 合わせた $C_{-\mathrm{NH} 2}$ は， $17 \mathrm{~K}$ 付近にこぶ状のピークを持ち，温度 とともに増加するカーブとなった。 これを，実測した過㮃熱容 量に合わせるようにスケーリングしたものが図 4 に示した奉 線である. 両者は良く一致しており，これから粒子表面には約 $1.5 \mathrm{~mol} \%$ の $\mathrm{NH}_{2}$ 基が存在すると仮定すると過剩熱容量を再 現することになる.

\section{5. 結 論}

イミド熱分解法で合成された比表面積の異なる高純度 $\alpha$ $\mathrm{Si}_{3} \mathrm{~N}_{4}$ 粉末の低温熱容量測定を行った結果, 高比表面積の試料 Bには, $18 \mathrm{~K}$ 付近にこぶ状の過剰熱容量が観測された。 ${ }^{1} \mathrm{H}-\mathrm{NMR}$ 測定及び IR 測定から $\mathrm{Si}_{3} \mathrm{~N}_{4}$ 粒子表面上には， $-\mathrm{NH}_{2}$ 基や一 $\mathrm{OH}$ 基などの表面官能基が存在することが示唆されたの で表面一 $\mathrm{NH}_{2}$ 基の自由回転運動を考慮に入れたモデルの熱容 量を計算し，実験結果を再現することができた。

表面官能基の運動を，回転運動を考慮に入れて計算すると実 測した熱容量をうまく説明することができる.しかしながら， 熱交換用の $\mathrm{He}$ などのガスが粒子表面に吸着しても同様な振る 舞いをすることから，これら吸着ガスによる過唾熱容量である 可能性も考えられる. 表面の結合状態に関する更に詳細な研究 が必要である。

\section{文献}

1) L. Bergstrom, Ceram. Trans., 44, 77-87 (1994).

2) T. Yamada, Am. Ceram. Soc. Bull., 72, 99-106 (1993).

3) T. Atake, H. Kawaji. A. Hamono and Y. Saito, Report Res. Lab. Eng. Mater. Tokyo Inst. Technol., 15, 13 (1990).

4) M. W. Chase, Jr., C. A. Davies, J. R. Downey, Jr., D. J. Frurip, A. R. McDonal and A. N. Syverd, J. Phys. Chem. Ref. Data, 14, Supp. 1 (1985)

5) Y. Yue, D. Li and C. Ye, J. Mater. Sci., 15, 1079-80 (1996).

6) G. Ramis, G. Busca and V. Lorenzelli, NATO ASI Ser., Ser., E: Appl. Sci., 173, 173-84 (1989).

7) I. Markichev, E. Sheka, N. Goncharova, I. Natkainec, A. Muzychka, V. Chukalin, V. Khavryutchenko and E. Nikitina, Physica B, 198, 200-02 (1994).

8) E. Sheka, V. Khavryutchenko, E. Nikitina, I. Natkaniec, I. Markichev, N. Goncharvova and V. Chukalin, J. Electron Spectrosc. Rela. Phenom., 67, 133-39 (1994). 